\title{
Analysis and validation of a Parkinson's disease register as a recruitment tool for clinical studies
}

\author{
Camille B Carroll $^{1 *}$, Amy Palmer ${ }^{2}$, Christine Cosby², John P Zajicek ${ }^{3}$ \\ From Clinical Trials Methodology Conference 2011 \\ Bristol, UK. 4-5 October 2011
}

\section{Background}

Many patients with Parkinson's disease (PD) are not afforded the opportunity to participate in clinical studies. A register of research-interested patients could improve involvement. We have established a register of research-interested PD patients within the South West of England, with pragmatic inclusion criteria and multiple routes of recruitment.

\section{Purpose}

To determine whether a register of PD patients interested in research could be established in a resource-efficient manner, and whether in comparison with traditional recruitment methods, the register would provide a more representative patient cohort and facilitate rapid and inclusive recruitment to clinical studies.

\section{Methods}

We undertook a comprehensive analysis of the register three years after it was initiated, including documentation of the pitfalls and benefits of its establishment, investigation of its utility as a recruitment tool and a survey of recruiters.

\section{Results}

There were 529 active participants $(\mathrm{M}: \mathrm{F}=1.6: 1)(589$ recruits, 60 withdrawn): mean age 71.4 yrs; mean disease duration 8.8 yrs from symptom onset, 7.2 yrs from diagnosis. $30 \%$ of register participants were self-referred; $70 \%$ were recruited by a healthcare practitioner. Local factors such as the availability of research support staff influenced recruitment. Response rate to annual

\footnotetext{
* Correspondence: camille.carroll@pms.ac.uk

${ }^{1}$ Peninsula College of Medicine and Dentistry, Dept Clinical Neurobiology, University of Plymouth, John Bull Building, Tamar Science Park, Plymouth, Devon, PL6 8BU, UK

Full list of author information is available at the end of the article
}

questionnaires was $86.5 \%$. There was a self-reported PD diagnosis rate of $92 \%$ at baseline, $88 \%$ at month 12 and $83 \%$ at month 24 . Total staff time required for pack preparation, recruitment and data entry was 15 minutes for each new recruit, and 5 minutes for each follow-up questionnaire. $85 \%$ of recruiters felt the register was a useful means of facilitating research and providing data for planning of service provision. In our feasibility study, a single mailing to participants resulted in a final recruitment rate that was double that achieved by traditional face-to-face recruitment.

\section{Limitations}

Despite $30 \%$ of participants self-referring to the register, all patients on the register were being seen in secondary care, either by a neurologist $(40 \%)$ or a geriatrician with a specialist interest in movement disorders (60\%). We have therefore yet to demonstrate access to a population that could not be accessed by traditional secondary-care based recruitment methods, and will be targeting register recruitment specifically in primary care to address this.

\section{Conclusions}

We have established a register of research-interested PD patients in a resource-efficient and pragmatic manner, which has the potential to maximise inclusivity and clinical research opportunities.

\section{Acknowledgements}

This work was supported by the Dementias and Neurodegenerative Diseases Network.

\section{Author details}

${ }^{1}$ Peninsula College of Medicine and Dentistry, Dept Clinical Neurobiology, University of Plymouth, John Bull Building, Tamar Science Park, Plymouth, Devon, PL6 8BU, UK. ${ }^{2}$ South West Dementias and Neurodegenerative Diseases Research Network, ITTC Building, Tamar Science Park, Plymouth, Devon, PL6 8BX, UK. ${ }^{3}$ Peninsula College of Medicine and Dentistry, University 
Published: 13 December 2011

doi:10.1186/1745-6215-12-S1-A118

Cite this article as: Carroll et al: Analysis and validation of a Parkinson's disease register as a recruitment tool for clinical studies. Trials 201112 (Suppl 1):A118.

Submit your next manuscript to BioMed Central and take full advantage of:

- Convenient online submission

- Thorough peer review

- No space constraints or color figure charges

- Immediate publication on acceptance

- Inclusion in PubMed, CAS, Scopus and Google Scholar

- Research which is freely available for redistribution 